This item was submitted to Loughborough's Research Repository by the author.

Items in Figshare are protected by copyright, with all rights reserved, unless otherwise indicated.

\title{
The long-term consequences of preterm birth: what do teachers know?
}

\section{PLEASE CITE THE PUBLISHED VERSION}

http://dx.doi.org/10.1111/dmcn.12683

\section{PUBLISHER}

Wiley (@ Mac Keith Press)

\section{VERSION}

AM (Accepted Manuscript)

\section{PUBLISHER STATEMENT}

This work is made available according to the conditions of the Creative Commons Attribution-NonCommercialNoDerivatives 4.0 International (CC BY-NC-ND 4.0) licence. Full details of this licence are available at: https://creativecommons.org/licenses/by-nc-nd/4.0/

\section{LICENCE}

CC BY-NC-ND 4.0

\section{REPOSITORY RECORD}

Johnson, Samantha, Camilla K. Gilmore, lan Gallimore, Julia Jaekel, and Dieter Wolke. 2019. "The Long-term Consequences of Preterm Birth: What Do Teachers Know?”. figshare. https://hdl.handle.net/2134/17011. 


\section{The long term consequences of preterm birth: What do teachers know?}

Samantha Johnson. Senior Research Fellow, Department of Health Sciences, University of Leicester, 22-28 Princess Road West, Leicester, LE1 6TP, UK.

Camilla Gilmore. Senior Research Fellow, Mathematics Education Centre, Loughborough University, Loughborough, LE11 3TU, UK.

Ian Gallimore. Study Manager, Department of Health Sciences, University of Leicester, 22-28 Princess Road West Leicester, LE1 6TP, UK.

Julia Jaekel. Research Associate, Department of Developmental Psychology, Ruhr-University Bochum, 44780 Bochum, Germany.

Dieter Wolke. Professor of Developmental Psychology and Individual Differences, Department of Psychology and Division of Mental Health and Wellbeing, Warwick Medical School, University of Warwick, University Road, Coventry, CV4 7AL, UK.

Manuscript word count: 2498

Corresponding author: Dr Samantha Johnson, Department of Health Sciences, University of Leicester, 22-28 Princess Road West, Leicester, LE1 6TP, UK. Tel: 0116252 5444. Fax: 0116252 3272. Email:sjj19@le.ac.uk.

Abbreviations: PB-KS - Preterm Birth Knowledge Scale; SEN - Special Educational Needs; TA - Teaching Assistant.

Keywords: preterm birth; neurodevelopmental outcomes; learning disabilities, special educational needs.

Disclosures: The authors have no conflicts of interest to disclose 


\section{Abstract}

Aim: The knowledge and information needs of education professionals was assessed to determine how prepared they are to support the growing number of preterm children entering schools today. Method. In a national survey, 585 teachers and 212 educational psychologists completed the Preterm Birth-Knowledge Scale to assess knowledge of outcomes following preterm birth. Total scores (range 0-33) were compared between groups and the impact of demographic characteristics on knowledge was analysed. Training and information needs were also assessed.

Results. Teaching staff (mean 14.7; SD 5.5) had significantly lower knowledge scores than educational psychologists (mean 17.1; SD 5.0; $<<0.001$ ); both had significantly lower scores than clinicians surveyed previously (mean 26.0; SD 3.6; $<<0.001$ ). Education professionals' poorest areas of knowledge related to the most frequent adverse outcomes following preterm birth. Only $16 \%$ of teaching staff received training about preterm birth and $>90 \%$ requested more information. Having a special educational needs role and being employed $\geq 16$ years were associated with higher knowledge scores.

Interpretation. Education professionals have poor knowledge of the needs of preterm children and most feel ill-equipped to support them in school. As teachers have primary responsibility for providing long-term support for preterm children this is of significant public health and educational concern.

\section{What this paper adds}

- Teachers and educational psychologists have poor knowledge of the outcomes of children born preterm, especially in areas most commonly affected by preterm birth.

- The vast majority have not received formal training in this area and feel ill-equipped to support preterm children in school.

- There is an urgent need to disseminate information about preterm birth to teachers and psychologists to bridge the knowledge gap between healthcare and education professionals.

Short title: Education professionals' knowledge of preterm birth 
Compared with term-born peers, children born very preterm ( $<32$ weeks gestation) are at increased risk for neurodevelopmental sequelae, such as cerebral palsy, vision and hearing impairments. ${ }^{1}$ However, cognitive and behavioural problems, particularly inattention, peer relationship problems and deficits in executive functions, are far more prevalent and account for the majority of functional disability in this population. ${ }^{2,3}$ Whilst most research has focused on children born very preterm ${ }^{1}$, recent studies have demonstrated a dose-response relationship with adverse outcomes across the full spectrum of preterm gestations $\left(<37\right.$ weeks). ${ }^{4,5}$

Although the vast majority of preterm children attend mainstream schools, they have poorer academic attainment ${ }^{6-8}$, particularly in mathematics ${ }^{9}$, and a higher prevalence of special educational needs (SEN) than term-born peers. ${ }^{7,}{ }^{10}$ With improved survival rates for extremely preterm births $(<26$ weeks ${ }^{11}$ and an increasing proportion of babies delivered at late preterm gestations (34-36 weeks), ${ }^{12}$ more preterm children will enter school in the coming years. Preterm birth has profound societal and economic consequences; after discharge from hospital, the greatest costs associated with prematurity lie not in healthcare but in education. ${ }^{13}$ This will challenge education systems worldwide as their professionals must try to respond to the needs of this growing population.

Previous studies have shown that teachers lack formal training and knowledge about chronic health conditions and the impact of these on children's adaptation at school. ${ }^{14-17}$ This is despite teachers' knowledge and preparation about such conditions being considered crucial for appropriate educational management. ${ }^{14,15}$ Teachers' attitudes to children with SEN are important for educational achievement because they need to feel confident about how to support such children in order to meet their needs in the classroom. ${ }^{18}$ Given current preterm birth rates $(10 \%)$, three children in an average mainstream UK class of 30 children are likely to have been born preterm. ${ }^{19}$ As such, nearly every education professional will be responsible for supporting a preterm child. Despite this, education professionals' knowledge of the outcomes and educational needs of preterm children has not been investigated, and it is not known whether they feel equipped to support the learning of preterm children. The objective of the present study was to assess the knowledge and information needs of education professionals relating to the consequences of preterm birth.

\section{METHODS}

\section{Participants and procedure}

(i) To assess knowledge and information needs of teaching staff, an email was sent to the head teacher of every school in England requesting them to cascade it to their staff. This included information about the study and a weblink to an online survey ${ }^{20}$ Posters describing the study and providing the web address of the survey were also sent to all schools in four local counties (Leicestershire, Nottinghamshire, Derbyshire, Warwickshire) inviting teaching staff to participate. (ii) To solicit the views of educational psychologists, an email was sent to all members of the Association for Educational Psychologists (AEP), the professional organisation for educational psychologists in the UK. This included information about the study and a weblink to the online survey.

Social media resources were also used to invite teachers and educational psychologists to participate. The study was approved by the University of Warwick Humanities and Social Sciences Research Ethics Committee (Ref 52/12-13).

\section{Measures}

Education professionals' knowledge of the outcomes of prematurity was assessed using the Preterm Birth-Knowledge Scale (PB-KS; Appendix A). ${ }^{21}$ This comprises 33 statements with forced choice responses (true, false, don't know). Each statement is evidence-based and was developed from a review of literature relating to outcomes following preterm birth. During scale development the statements were reviewed by experts in the field to assess content validity and accuracy. Responses on individual statements are scored for accuracy based upon current knowledge (don't know/incorrect $=0$; correct $=1$ ) and a total knowledge score (range $0-33$ ) is computed (higher scores 
indicate greater knowledge); a percent accuracy score can also be computed to measure the proportion of correct responses across PB-KS items. The PB-KS has excellent internal reliability (Cronbach's Alpha $0.82^{21}$ ); in this sample: Teaching staff 0.81, Educational psychologists 0.77 ) and construct validity discriminating the knowledge levels of neonatal clinicians and education practitioners. ${ }^{21}$ The surveys also explored opinions about who is likely to be responsible for supporting preterm children and the value of disclosing a child's preterm birth status. Self-perceived competence in supporting a preterm child, adequacy of training received, and information needs were also assessed with responses recorded on a 5-point Likert scale (strongly disagree; disagree; neither agree nor disagree; agree; strongly agree; see Appendix B). Items were also included to elicit information about demographic characteristics (Table 1); as these data were non-identifiable participation was anonymous.

\section{Statistical analyses}

Data were analysed using SPSS v20. Differences between teachers and educational psychologists in PB-KS scores were assessed using independent samples t-tests. To assess the effect of demographic characteristics on knowledge levels, the association between demographic variables and PB-KS scores were analysed separately for teaching staff and educational psychologists using independent samples t-tests or linear regression as appropriate. Multivariable linear regression was used to assess the independent effect of demographic variables on knowledge scores. Differences in demographic characteristics between respondents and national data for teachers and educational psychologists were assessed using chi-square tests.

\section{RESULTS}

\section{Characteristics of respondents}

In total, 830 staff responded to the school survey, of which 734 (88\%) were teaching staff; $70(8 \%)$ non-teaching staff and $4 \%$ with missing demographic data were excluded. Overall, 679 teaching staff answered the PB-KS, of whom $585(80 \%)$ completed all 33 items. Of these, $381(65 \%)$ were employed in community, voluntary aided or controlled schools, 142 (24\%) in academies or free schools and $62(11 \%)$ in independent schools. Respondents represented a wide range of ages of children taught with $36 \%$ teaching children aged $3-5$ years, $46 \%$ ages $5-7,48 \%$ ages $7-11,37 \%$ ages $11-14,36 \%$ ages $14-16$ and $24 \%$ ages 16-18. Detailed demographic characteristics of these respondents are shown in Table 1. Compared with national data for staff in publicly funded schools $^{22}$, respondents were significantly more likely to be female $(86 \%$ vs. $83 \% ; \mathrm{p}=0.031)$, to be teachers rather than teaching assistants (TAs) $(93 \%$ vs. $58 \%, \mathrm{p}<0.001)$ and to be from special schools $(18 \%$ vs. $7 \%, \mathrm{p}<0.001)$.

\section{$<$ TABLE $1>$}

Overall, 262 educational psychologists responded, of which 212 (81\%) completed the PB-KS. Most respondents were female, qualified and employed in local government (Table 1). Compared with national data, respondents were significantly more likely to be female $(86 \%$ vs. $79 \%, \mathrm{p}=0.01)$ and full members vs. trainees/affiliate/retired (91\% vs. $85 \%$, $\mathrm{p}=0.02)$.

\section{Knowledge of preterm birth}

The mean knowledge score for teaching staff was 14.7 (SD 5.5; range 0-27) which equated to a mean accuracy of $45 \%$ (SD 17\%); $15(2.6 \%)$ scored zero and $12 \%$ responded with $<25 \%$ accuracy. The mean total knowledge score of educational psychologists was 17.1 (SD 5.0; range 1-28) equating to $52 \%$ (SD 15\%) accuracy; $11(5.2 \%)$ responded with $<25 \%$ accuracy and none had scores of zero.

Teaching staff had significantly lower scores than psychologists $(\mathrm{t}(795)=-5.411, \mathrm{p}<0.001)$.

Compared with data of neonatal clinicians obtained in a previous study $(n=70 \text {, mean 26.0, SD 3.6 })^{21}$, both teaching staff and educational psychologists had significantly lower scores with a mean deficit of $11.2(\mathrm{t}(653)=-22.9, \mathrm{p}<0.001)$ and 8.9 points $(\mathrm{t}(280)=16.1, \mathrm{p}<0.001)$ respectively. 
The effect of demographic characteristics on knowledge scores is shown in Table 1. Teaching staff in special schools had significantly higher scores than those in mainstream schools, and those with a SEN Coordinator (SENCO) role had higher scores than other mainstream teaching staff. Being employed for $\geq 16$ years was associated with significantly higher scores as was being female. On multivariable analyses, gender, special school and employment $\geq 16$ years were independently associated with higher knowledge scores. Among psychologists, there was no difference in knowledge scores by sex, membership status or number of years employed (Table 1).

\section{Specific areas of knowledge}

The accuracy of respondents' scores on PB-KS items is shown in Figure 1. Although teaching staff had poorer knowledge than psychologists, the profile of responses was similar between groups. Only $8 \%$ of teachers knew that maths difficulties are a particular deficit following preterm birth and $88 \%$ held the erroneous belief that most very preterm children will experience developmental delays as a toddler; only $11 \%-18 \%$ knew that very preterm children are likely to be inattentive and have poorer social skills than term-born children. Psychologists also displayed $11 \%-18 \%$ accuracy in these areas. In both groups greatest accuracy was demonstrated on items relating to neurosensory sequelae such as cerebral palsy and the need for assistance with daily functions.

\section{$<$ FIGURE 1>}

\section{Information needs}

As shown in Figure 2, $>90 \%$ of respondents felt they were likely to come into contact with a preterm child and most felt that educational management was the responsibility of the class teacher. Around $3 / 4$ reported that disclosure of preterm birth status would be beneficial for the child; however, only $38 \%$ of teaching staff felt adequately equipped to support preterm children and just $14 \%$ felt they had received sufficient training in this area. Over $80 \%$ of respondents requested more information about preterm birth. Only $16 \%$ of teaching staff had received formal training about preterm birth and only $3.1 \%$ as part of their initial teacher training (Figure 3 ).

\section{$<$ FIGURE $2><$ FIGURE $3>$}

Respondents who felt adequately equipped to support a preterm child had significantly higher knowledge scores than those who felt ill-equipped (Table 1); however, mean scores of teaching staff and psychologists who felt adequately equipped were still 10 and 8 points lower than those of neonatal clinicians, respectively. Teaching staff who felt they had received sufficient training had significantly higher knowledge scores than those who lacked training, but there was no difference in psychologists' scores between those who felt sufficiently trained or not (Table 1).

\section{DISCUSSION}

The results of this study show that teachers and educational psychologists have remarkably poor knowledge of the impact of preterm birth on children's learning and development, and only a small minority feel sufficiently trained to support these children in school. After discharge from neonatal care, the greatest cost of prematurity lies within the education system ${ }^{13}$ where these children require long-term support for cognitive and behavioural problems to allow for later life success. ${ }^{23}$ Given that almost all teachers will be responsible for the management of a preterm child during their career, these results are of significant public health and educational concern.

Typically, only very preterm infants are followed-up by neonatal services to two years corrected age, ${ }^{24}$ ${ }^{25}$ after which point those without severe disabilities are discharged from care. Thus the overwhelming majority of preterm survivors receive no developmental surveillance during the preschool years when learning difficulties may become exacerbated or emerge. Schools thus provide the next routine point of contact for these children and educational professionals are increasingly charged with identifying and responding to these needs. 
Teachers and educational psychologists in this study had knowledge scores that were 2 SD below those of neonatal clinicians. This represents a large and substantial gap in knowledge. Although educational psychologists had slightly better knowledge than teaching staff, there was only $0.5 \mathrm{SD}$ difference in scores. Notably, both groups had a similar profile of knowledge scores indicating similar areas of greatest, and indeed poorest, knowledge. Worryingly, the areas of poorest knowledge related to the most common adverse outcomes following preterm birth, specifically mathematics difficulties, peer relationship problems and inattention. ${ }^{9,26,27}$ This suggests that preterm children may not receive support in the areas they need it the most.

Identifying difficulties and providing appropriate support is further compounded by the special constellation of problems associated with preterm birth. Preterm children have been described as a new generation of children with complex learning difficulties that are different in nature from previous generations of children with SEN. ${ }^{28}$ Indeed, in terms of $\mathrm{ADHD}^{29}, \mathrm{ASD}^{30}$ and mathematics learning difficulties ${ }^{31}$, the problems of very preterm children appear to have different developmental mechanisms compared with those of term-born children with these difficulties. The preterm behavioural phenotype, characterised by inattention, anxiety and social problems alongside a notable absence of an increased risk for hyperactivity/impulsivity and conduct disorders, ${ }^{2}$ means that preterm children are unlikely to be disruptive in the classroom and their problems may be missed in school. ${ }^{26}$ Education professionals' paucity of knowledge identified here thus raises substantial concern that preterm children's difficulties may go undetected, especially in the areas of greatest need.

It is perhaps unsurprising that education professionals feel unprepared to meet the needs of these children. Teachers have been shown to have a paucity of knowledge and training regarding the needs of children with chronic health conditions. ${ }^{15-17}$ The study of the sequelae of prematurity is a relatively new field within clinical research and, as yet, little consideration has been paid to disseminating this evidence to education professionals. Only $16 \%$ of teaching staff had received formal training about preterm birth, and only $3 \%$ as part of their initial teacher training. Greater knowledge levels were found among those who had a SEN role and those who had been teaching for over 16 years. Coupled with higher knowledge scores among educational psychologists, this suggests that, at present, knowledge of the needs of preterm children is acquired through greater opportunity for professional experience of supporting a preterm child. From September 2014, the UK SEN Code of Practice will require greater collaboration between health, education and social care services for supporting young people with additional needs. ${ }^{32}$ It is thus imperative that information about preterm birth is communicated to education professionals to bridge the gap in knowledge between those working in the healthcare and education systems. Identifying difficulties has been shown to have a positive effect on outcomes for children with ADHD but only when combined with practical advice about educational management. ${ }^{33}$ It is essential that information about the impact of preterm birth is disseminated to education professionals, but also that they are provided with strategies for supporting children in the classroom. There is thus an urgent need for the development and evaluation of educational interventions for improving academic outcomes in preterm children.

\section{Strengths and limitations}

The strengths of this study lie in the use of a validated scale to assess knowledge of preterm birth and the recruitment of teachers from across England and educational psychologists throughout the UK. However, the study is limited by the sample size. Despite using personalised emails to head teachers of all 24,000 schools in England, only 734 members of teaching staff responded. Engaging teachers in research is notoriously difficult ${ }^{34}$, but the low response rate here may reflect the poor understanding of this subject and a perception that prematurity is not a concern for education professionals. Indeed, respondents were more likely to be female, have an SEN role and to be from special schools compared with national statistics, variables that were all associated with higher knowledge scores. As individuals with a particular interest in prematurity are likely to have responded we believe our results may underestimate the true paucity of knowledge of education professionals in the UK.

\section{Conclusions}

Education professionals lack knowledge of the impact of preterm birth on children's learning and development and feel ill equipped to support these children in school. As their areas of poorest knowledge relate to the most common adverse outcomes following preterm birth, preterm children 
may not be receiving support in the areas they need it the most. Training education professionals about preterm birth is crucial in preparing them to support preterm children in school. This presents a global challenge as the 15 million babies born prematurely each year continue to enter their respective education systems. 


\section{Acknowledgements}

The authors would like to thank the UK Association of Educational Psychologists for their support for this study. We also acknowledge the work of Dr Charlotte Beer, University of Nottingham, for her contribution to the development of the Preterm Birth-Knowledge Scale in previous studies. This study was funded by a Nuffield Foundation grant to Drs Wolke, Johnson, Gilmore \& Jaekel (Ref: EDU/40442). Dr Gilmore is supported by a Royal Society Dorothy Hodgkin Fellowship. The funders were not involved in the design, data collection and analysis and manuscript preparation. 


\section{References}

1. Saigal S, Doyle L. An overview of mortality and sequelae of preterm birth from infancy to adulthood. Lancet. 2008; 371: 261-9.

2. Johnson S, Marlow N. Preterm Birth and Childhood Psychiatric Disorders. Pediatr Res. 2011; 69(5): $11 \mathrm{r}-8 \mathrm{r}$.

3. Mulder H, Pitchford NJ, Hagger MS et al. Development of executive function and attention in preterm children: A systematic review. Dev Neuropsych. 2009; 34(4): 393-421.

4. de Jong M, Verhoeven M, van Baar AL. School outcome, cognitive functioning, and behaviour problems in moderate and late preterm children and adults: a review. Semin Fetal Neonatal Med. 2012; 17(3): 163-9.

5. Moster D, Terje R, Markestad T. Long-term medical and social consequences of preterm birth. N Engl J Med. 2008; 359: 262-73.

6. Quigley MA, Poulsen G, Boyle E et al. Early term and late preterm birth are associated with poorer school performance at age 5 years: a cohort study. Arch Dis Child Fetal Neonatal Ed. 2012; 97(3): F167-73.

7. Johnson S, Hennessy E, Smith R et al. Academic attainment and special educational needs in extremely preterm children at 11 years. The EPICure Study. Arch Dis Child Fetal Neonatal Ed. 2009; 94: F283-F9.

8. Mathiasen R, Hansen BM, Andersen AM et al. Gestational age and basic school achievements: a national follow-up study in Denmark. Pediatrics. 2010; 126(6): e1553-61.

9. Simms V, Cragg L, Gilmore $\mathrm{C}$ et al. Mathematics difficulties in children born very preterm: current research and future directions. Arch Dis Child Fetal Neonatal Ed. 2013; 98(5): F457-63.

10. Saigal S, den Ouden L, Wolke D et al. School-age outcomes in children who were extremely low birth weight from four international population-based cohorts. Pediatrics. 2003; 112(4): 943-50.

11. Costeloe K, Hennessy E, Haider S et al. Short term outcomes after extreme preterm birth in England: comparison of two birth cohorts in 1995 and 2006. BMJ. 2012; 345: e7976.

12. March of Dimes. March of Dimes Peristats. March of Dimes Foundation; 2014; Available from: http://www.marchofdimes.com/peristats/Peristats.aspx.

13. Petrou S, Abangma G, Johnson S et al. Costs and health utilities associated with extremely preterm birth: evidence from the EPICure study. Value Health. 2009; 12(8): 1124-34.

14. Johnson MP, Lubker BB, Fowler MG. Teacher Needs Assessment for the Educational Management of Children with Chronic Illnesses. J Sch Health. 1988; 58(6): 232-5.

15. Brook U, Galili A. Knowledge and attitudes of high school teachers towards pupils suffering from chronic diseases. Patient Educ Couns. 2001; 43(1): 37-42.

16. Clay DL, Cortina S, Harper DC et al. Schoolteachers' experiences with childhood chronic illness. Childrens Health Care. 2004; 33(3): 227-39.

17. Nabors LA, Little SG, Akin-Little A et al. Teacher knowledge of and confidence in meeting the needs of children with chronic medical conditions: Pediatric psychology's contribution to education. Psychol Sch. 2008; 45(3): 217-26.

18. Florian L, Black-Hawkins K. Eploring inclusive pedagogy. Br Educ Res. 2010; 37(5): 813-28.

19. Hornby G \& Woodward LJ. Education needs of school-aged children born very and extremely preterm: A review. Educ Psychol Rev. 2009;21:247-266.

20. SurveyMonkey. 2014; (18/02/2014). Available from: http://www.surveymonkey.com/.

21. Henderson D, Beer C, Wolke D et al. Development and validation of a scale to assess knowledge of outcomes following preterm birth. Arch Dis Child. 2012; 97(Suppl 2): A353.

22. Department for Education. School workforce in England: November 2013. London:

Department for Education; 2014. https://www.gov.uk/government/publications/school-workforce-inengland-november-2013.

23. Goodman A, Joyce R, Smith JP. The long shadow cast by childhood physical and mental problems on adult life. Proc Natl Acad Sci. 2011; 108(15): 6032-7.

24. British Association of Perinatal Medicine. Report of a BAPM/RCPCH Working Group:

Classification of health status at 2 years as a perinatal outcome. London: BAPM, 2008.

25. NHS \& Department for Health. Toolkit for High Quality Neonatal Services. London:

Department of Health; 2009. 
26. Brogan $\mathrm{E}$, Cragg L, Gilmore $\mathrm{C}$ et al. Inattention in very preterm children: implications for screening and detection. Arch Dis Child 2014; 99: 834-839.

27. Johnson S, Wolke D. Behavioural outcomes and psychopathology during adolescence. Early Hum Dev. 2013; 89: 188-207.

28. The Schools Network. Schools are facing a new generation of children with complex special needs and disabilities and special needs, says new research. The Specialist Schools and Academies Trust; 2009 [cited 2011 23/11/11]; Available from:

https://www.ssatrust.org.uk/media/Pages/Schoolsarefacinganewgenerationofchildrenwithcomplexspec ialneedsanddisabilitiesandspecialneeds, saysnewresearch.aspx.

29. Johnson S, Hollis C, Kochhar P et al. Psychiatric Disorders in Extremely Preterm Children: Longitudinal Finding at Age 11 Years in the EPICure Study. J Am Acad Child Adolesc Psychiatr. 2010; 49(5): 453-63.

30. Johnson $\mathrm{S}$, Hollis $\mathrm{C}$, Kochhar $\mathrm{P}$ et al. Autism spectrum disorders in extremely preterm children. J Pediatr. 2010; 156(4): 525-31 e2.

31. Simms V, Gilmore C, Cragg L et al. The nature and origins of mathematics difficulties in very preterm children: A different aetiology than Developmental Dyscalculia. Pediatr Res. In press.

32. Department for Education, Department of Health. Draft Special Educational Needs (SEN) Code of Practice: of 0 to 25 years. London: 2013.

33. Tymms $\mathrm{P}$, Merrell C. The impact of screening and advice on inattentive, hyperactive and impulsive children. Eur J Spec Needs Educ. 2006; 21(3): 321-37.

34. Sturgis P, Smith P, Hughes G. A study of suitable methods for raising response rates in school surveys: Research Report 721. London: 2006. 
Table 1. Demographic characteristics of teaching staff and psychologists who completed the Preterm Birth-Knowledge Scale (PB-KS) and associations with total PB-KS scores.

\begin{tabular}{|c|c|c|c|}
\hline Characteristic & $\mathrm{N}(\%)$ & $\begin{array}{c}\text { PB-KS } \\
\text { Mean (SD) }\end{array}$ & $\mathbf{p}$ \\
\hline \multicolumn{4}{|l|}{ Teaching staff $(n=585)$} \\
\hline \multicolumn{4}{|l|}{ School type } \\
\hline Mainstream & $480(82 \%)$ & $14.5(5.5)$ & 0.024 \\
\hline Special & $105(18 \%)$ & $15.8(5.6)$ & \\
\hline \multicolumn{4}{|l|}{ SEN Role [mainstream schools] ${ }^{b}$} \\
\hline SEN-Coordinator & $99(21 \%)$ & $16.4(4.6)$ & $<0.001$ \\
\hline Non SEN-Coordinator & $381(79 \%)$ & $14.0(5.6)$ & \\
\hline \multicolumn{4}{|l|}{ Qualified Teacher Status (QTS) } \\
\hline Has QTS & $528(90 \%)$ & $14.9(5.5)$ & 0.072 \\
\hline Does not have QTS & $57(10 \%)$ & $13.5(5.6)$ & \\
\hline \multicolumn{4}{|l|}{ Teacher vs. Teaching Assistant } \\
\hline Teacher & $348(934 \%)$ & $14.8(5.5)$ & 0.094 \\
\hline Teaching Assistant & $37(6 \%)$ & $13.3(5.7)$ & \\
\hline \multicolumn{4}{|l|}{ Head teacher role ${ }^{a}$} \\
\hline Head teacher role & $196(34 \%)$ & $15.2(5.7)$ & 0.205 \\
\hline Non-head teacher & $389(67 \%)$ & $14.5(5.4)$ & \\
\hline \multicolumn{4}{|l|}{ Years of employment [teachers only] ${ }^{c}$} \\
\hline$\leq 5$ years & $63(12 \%)$ & $12.9(5.9)$ & $0.003^{\mathrm{d}}$ \\
\hline $6-15$ years & $153(28 \%)$ & $14.4(4.8)$ & \\
\hline $16-25$ years & $177(32 \%)$ & $15.2(5.5)$ & \\
\hline $26-35$ years & $88(16 \%)$ & $14.9(5.9)$ & \\
\hline$\geq 35$ years & $67(12 \%)$ & $16.6(5.5)$ & \\
\hline \multicolumn{4}{|l|}{ Gender } \\
\hline Male & $95(16 \%)$ & $12.9(7.1)$ & 0.005 \\
\hline Female & $490(84 \%)$ & $15.1(5.1)$ & \\
\hline \multicolumn{4}{|l|}{ Equipped to support preterm children ${ }^{\mathrm{e}}$} \\
\hline Feel equipped & $223(38 \%)$ & $16.4(4.9)$ & $<0.001$ \\
\hline Feel ill-equipped & $359(62 \%)$ & $13.7(5.7)$ & \\
\hline \multicolumn{4}{|c|}{ Received sufficient training about prematurity ${ }^{\mathrm{e}}$} \\
\hline Sufficient training & $81(14 \%)$ & $16.9(5.9)$ & $<0.001$ \\
\hline Insufficient training & $501(86 \%)$ & $14.4(5.4)$ & \\
\hline \multicolumn{4}{|l|}{ Educational psychologists $(n=212)$} \\
\hline \multicolumn{4}{|l|}{ Gender } \\
\hline Male & $29(14 \%)$ & $16.0(5.4)$ & 0.227 \\
\hline Female & $183(86 \%)$ & $17.2(4.9)$ & \\
\hline \multicolumn{4}{|l|}{ Membership status } \\
\hline Fully qualified & $191(91 \%)$ & $17.0(4.9)$ & 0.793 \\
\hline Trainee/affiliate/retired & $20(10 \%)$ & $17.4(5.5)$ & \\
\hline \multicolumn{4}{|l|}{ Years of employment } \\
\hline$\leq 5$ years & $44(21 \%)$ & $16.7(5.0)$ & $0.964^{\mathrm{d}}$ \\
\hline $6-15$ years & $81(38 \%)$ & $17.0(4.8)$ & \\
\hline $16-25$ years & $49(23 \%)$ & $17.3(4.6)$ & \\
\hline $26-35$ years & $28(13 \%)$ & $17.3(6.4)$ & \\
\hline$\geq 35$ years & $10(5 \%)$ & $17.8(4.2)$ & \\
\hline \multicolumn{4}{|l|}{ Equipped to support preterm children } \\
\hline Feel equipped & $126(60 \%)$ & $17.9(4.8)$ & 0.003 \\
\hline Feel ill-equipped & $84(40 \%)$ & $15.8(5.1)$ & \\
\hline \multicolumn{4}{|c|}{ Received sufficient training about prematurity } \\
\hline Sufficient training & $53(25 \%)$ & $17.8(4.7)$ & 0.223 \\
\hline Insufficient training & $157(75 \%)$ & $16.8(5.1)$ & \\
\hline
\end{tabular}




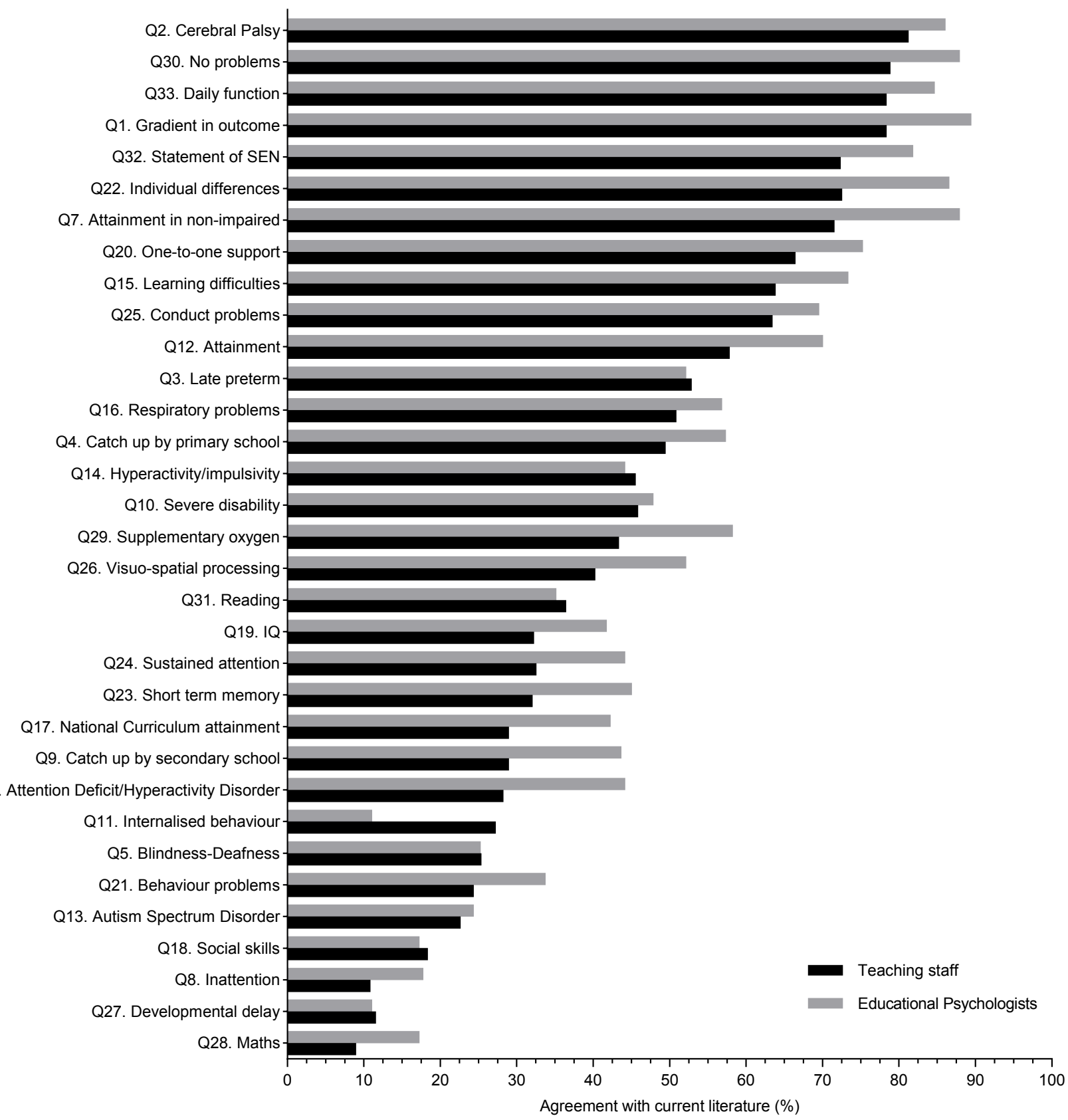

Figure 1. Proportion of correct responses on individual Preterm Birth-Knowledge Scale (PB-KS) items for teaching staff and educational psychologists. The y axis details the PB-KS statement number and a summary descriptor of the statement content. The full statement for each item is shown in Appendix A. 


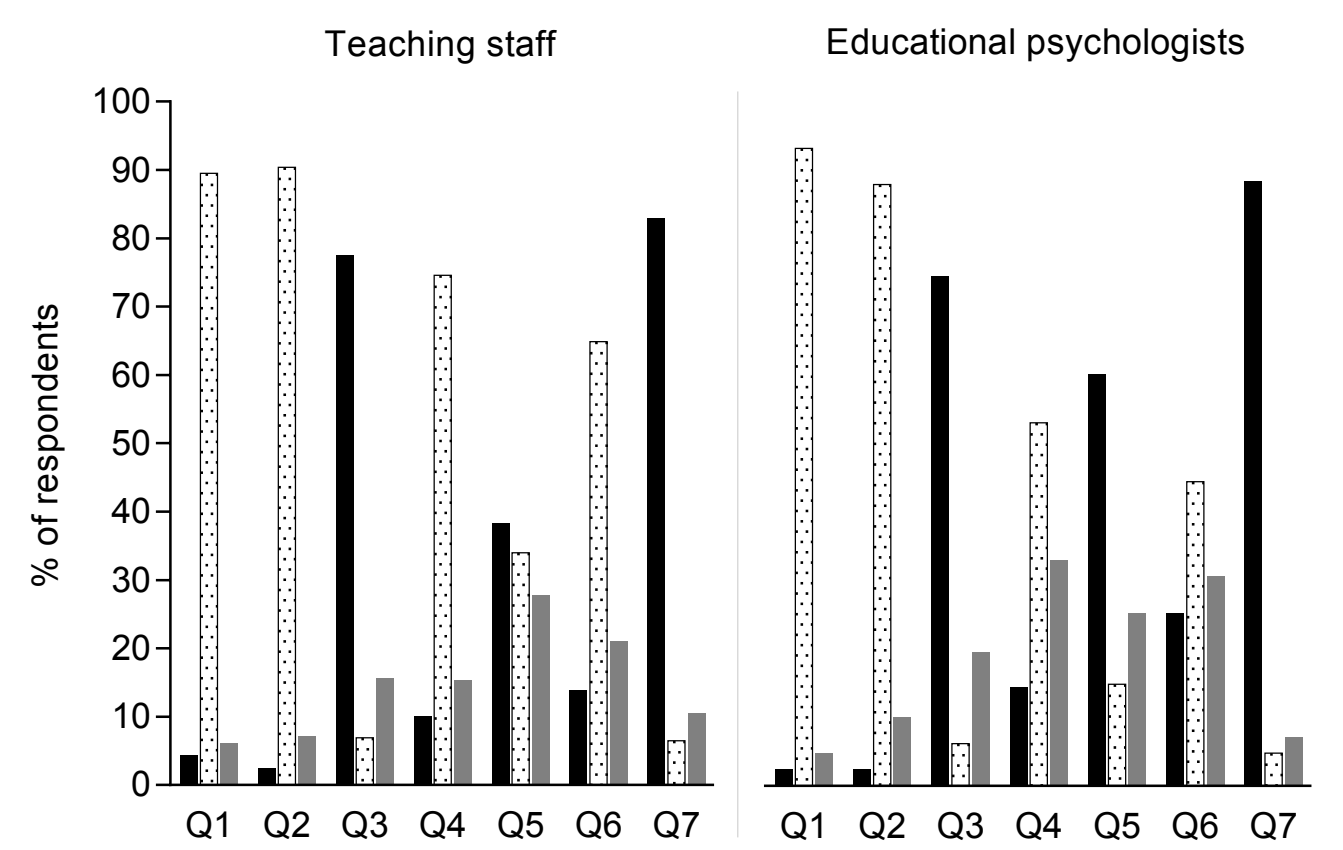

$\begin{array}{ll}\text { A... } & \text { Agree } \\ \text { Disagre }\end{array}$

Neither agree nor disagree

Q1. I am unlikely to come into professional contact with a child born very preterm.

Q2. Educational management of very preterm children is the job of the SENCO not the class teacher.

Q3. Disclosing a child's preterm birth status to the school would be beneficial for the child.

Q4. Disclosing a child's preterm birth status would lead to problems because of the negative effect of labeling.

Q5. I feel adequately equipped to support the learning and development of preterm children

Q6. I have received sufficient training in how to support the learning and development of preterm children.

Q7. I would like to know more about strategies I can use to help support the learning and development of preterm children.

Figure 2. Teaching staff and educational psychologists' opinions on issues relating to the education of preterm children (Q1-4) and on training received (Q57). 


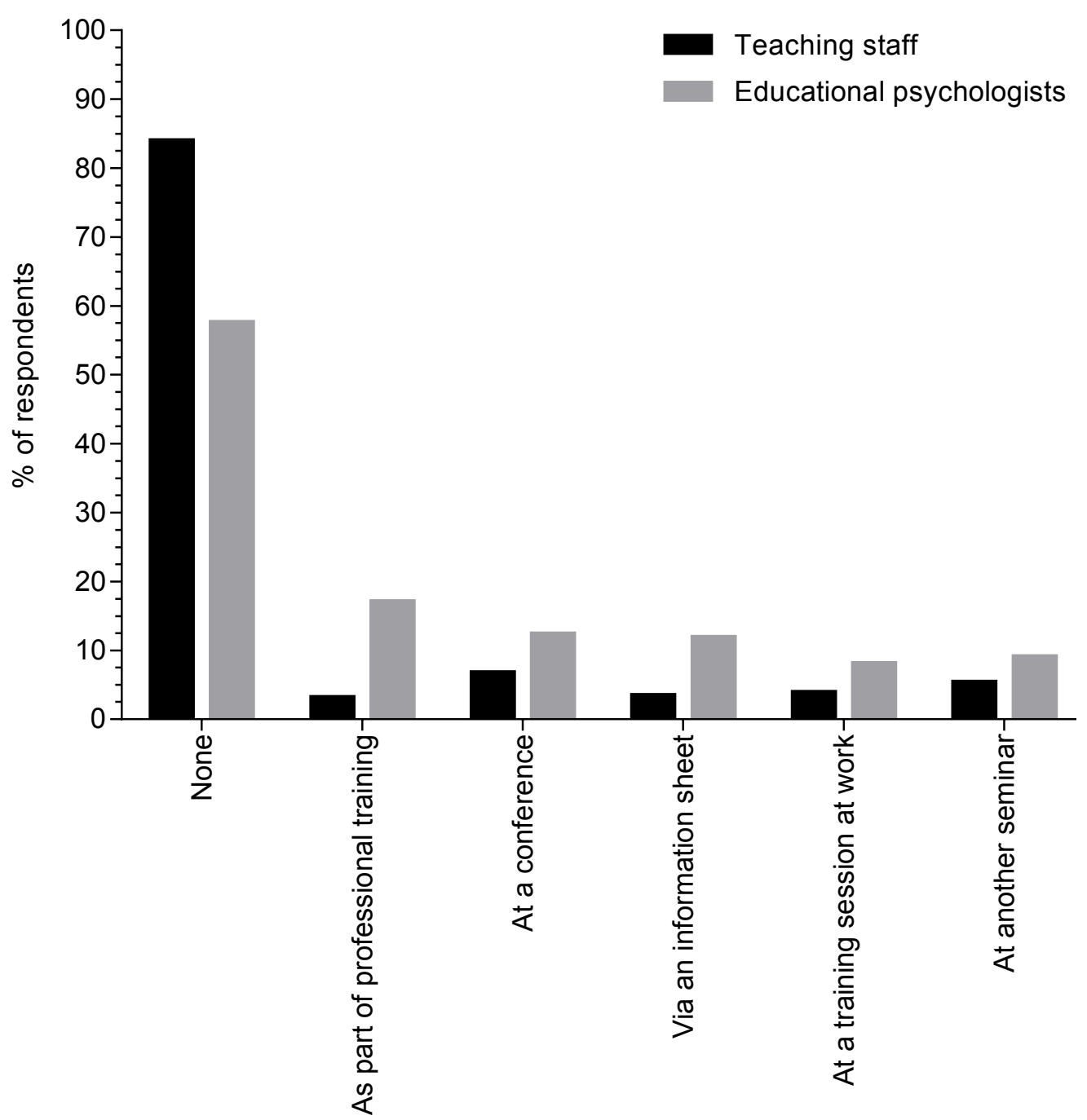

Figure 3. Proportion and method of formal training about preterm birth received by teac. and educational psychologists. 